\title{
Form und Materie bei Aristoteles
}

\author{
Vorarbeiten zu einer Interpretation der Substanzbücher
}



2015. IX, 346 Seiten. CM 11

ISBN 978-3-16-153715-8

DOI 10.1628/978-3-16-153715-8

eBook PDF $79,00 €$

ISBN 978-3-16-153666-3

fadengeheftete Broschur 79,00€
Der Begriff der Form bildet eines der Zentren des Aristotelischen Denkens. Seit längerer Zeit herrscht jedoch Uneinigkeit darüber, was genau Aristoteles darunter verstanden wissen wollte. Die Vorschläge reichen von der Identifizierung der Form mit der Art bis hin zur Behauptung, sie sei ganz im Gegenteil gerade etwas Individuelles, so daß die Form des Sokrates eine andere wäre als die Platons. Im Fokus der Auseinandersetzung stehen dabei die sogenannten Substanzbücher (Met. Z, H, $\Theta$ ). Dies hat zwar einen guten Grund, weil dort die Theorie der Form und damit die Ontologie des Aristoteles ihren Höhepunkt erreicht, ihr Voraussetzungsreichtum wird jedoch oft unterschätzt. Andreas Gasser versucht daher, die Entwicklung des FormBegriffs von der frühen Kategorienschrift bis zu seiner entscheidenden Modifikation durch die Einführung des komplementären Materie-Begriffs im ersten Buch der Physik nachzuzeichnen und dadurch einer neuen Interpretation der Substanzbücher den Boden zu bereiten.

Andreas Gasser Geboren 1977; 1999-2007 Studium der Philosophie und Soziologie; seit 2007 Mitarbeit am Projekt Alcuin (www.alcuin.de); seit 2008 Dozent an der Universität Regensburg; 2013 Promotion in Philosophie; derzeit Wissenschaftlicher Mitarbeiter am Lehrstuhl für Geschichte der Philosophie der Universität Regensburg.

Jetzt bestellen:

https://mohrsiebeck.com/buch/form-und-materie-bei-aristoteles-9783161537158?no_cache=1

order@mohrsiebeck.com

Telefon: +49 (0)7071-923-17

Telefax: +49 (0)7071-51104 